Article

\title{
Language Dominance, Verbal Fluency, and Language Control in two Groups of Russian-English Bilinguals
}

\author{
Elena Shishkin ${ }^{1}$ and Peter Ecke ${ }^{2, *}$ \\ 1 American Language and Culture Institute, California State University San Marcos, \\ 333 S. Twin Oaks Valley Road, San Marcos, CA 92096, USA; eshishkin@csusm.edu \\ 2 Department of German Studies, University of Arizona, 301 Learning Services Building, \\ Tucson, AZ 85721, USA \\ * Correspondence: eckep@email.arizona.edu; Tel.: +1-520-621-3202
}

Received: 14 March 2018; Accepted: 6 July 2018; Published: 14 July 2018

check for updates

\begin{abstract}
This study explored language dominance, verbal fluency, and language control abilities of two groups of younger and older Russian-English bilinguals who had spent similar amounts of time as immigrants in the U.S. Verbal fluency tasks (based on letter and semantic cues, including a new method to elicit parallel letter-fluency data for Russian and English) were used to measure the bilinguals' current lexical retrieval skills in addition to self-assessments of language proficiencies at time of study and time of arrival. Stroop tasks (naming colors with incongruent cues) were used to measure younger and older bilinguals' ability to control interference during color-naming. Findings demonstrate that the older immigrants were less fluent in L2 naming tasks and that they remained dominant (more proficient) in their L1 whereas the younger immigrants had become relatively balanced bilinguals in terms of proficiency, fluent in both the L1 and L2. Younger and older bilinguals were equally capable of controlling interference across and within the two languages. We propose that it is not balance in bilingual proficiency that positively affects language control abilities, but balance as stability of language systems. Stability of language systems can be achieved if bilingual usage patterns remain relatively constant over several years and if no radical changes in language learning and maintenance efforts are required.
\end{abstract}

Keywords: lexical retrieval; verbal fluency; Stroop task; interference; language control; dominance; Russian-English bilinguals

\section{Introduction}

What is the likelihood of immigrants to develop fluency and control in the language of the new home country, usually a second language (L2)? To what extent do they maintain first language (L1) fluency and manage cross-language interference in their languages? The present study attempted to shed light on these questions by investigating letter and semantic category fluency as well as language control abilities in two age groups of Russian-Jewish immigrants who for the most part came to the United States in the 1990s.

Young children of immigrant families usually have better prospects for ultimate attainment in an L2 than adults who start learning the L2 relatively late in life (Bylund et al. 2012; Flege 1999; Muñoz and Singleton 2011). However, young children (during the first decade of life) are also more vulnerable to L1 attrition than adults (Benmamoun et al. 2010; Ecke 2004; Isurin 2013; Schmid 2011) although even adults display dynamic changes in their ability to access multiple languages over time (De Bot and Lowie 2010; Ecke and Hall 2013; Opitz 2013). Immigrants of Russian origin in the U.S. have received considerable attention from researchers who investigated issues of L1 attrition (Isurin 2000, 2007; Laleko 2007; Pavlenko 2003), L2 influence on L1 (Mikhaylova 2006) 
as well as incomplete L1 acquisition and L1 (re)learning (Dubinina and Polinsky 2013; Isurin and Ivanova-Sullivan 2008; Polinsky 2006; Smyslova 2012). The present study contributes to this body of research by investigating cognitive aspects of Russian immigrants' language development, particularly their language dominance, verbal fluency, and ability to control their two languages.

Gained insights from such a study may be informative with respect to the educational and employment potential of this population (Andrews 2000; Benmamoun et al. 2010; Kagan and Dillon 2004). This study also makes a methodological contribution to the comparative study of verbal fluency in Russian and English through the identification of comparable letter cues as stimuli for experimental studies.

\subsection{Language Dominance, Verbal Fluency, and Interference in Lexical Retrieval}

Language dominance is one of the constructs widely used in the field of bilingualism (Montrul 2015). It refers to "observed asymmetries of skill in, or use of, one language over the other" (Birdsong 2014, p. 374). ${ }^{1}$ Here we equate dominant language(s) with most proficient language(s). Bilinguals who are dominant in one language are normally seen as bilinguals who are unbalanced in proficiency. Balanced bilinguals, on the other hand, are those who are equally proficient in the two or more languages they speak. These individuals are quite rare in real life (Grosjean and Li 2013; Myers-Scotton 2008). We will later present a different conception of balanced bilingualism. A bilingual may process speech more easily, and access lexical items faster in a more dominant language compared to a less dominant one. Language dominance, of course, can vary among different semantic domains, especially if the languages have been learned and used in different cultural and linguistic contexts (home, school, work, etc.).

Verbal (essentially lexical) fluency tasks have been applied to investigate language dominance and ease of lexical retrieval in bilingual and monolingual populations. In verbal fluency tasks, participants are asked to name in a limited time as many words as possible that start with a certain sound/letter (e.g., F) or semantic category (e.g., "animals").

Various studies compared lexical fluency in bilingual and monolingual speakers. In general, bilinguals have been found to be slower than monolinguals in the verbal fluency tasks, particularly when their search is constrained by semantic categories (Rosselli et al. 2000; Gollan et al. 2002; Portocarrero et al. 2007). Gollan et al. (2002) also found a bilingual disadvantage in fluency tasks constrained by letter-cues. The longer retrieval times needed by bilinguals have been explained to be a consequence of competition between lexical entries of the bilinguals' two languages, overall weaker connections between lexical forms and corresponding meanings in the bilingual lexicon due to lower word usage frequencies or a combination of both. However, the bilingual disadvantage in verbal fluency disappears or turns into an advantage when monolingual and bilingual groups have similar levels of vocabulary size in the response language (Escobar et al. 2018).

Some studies applied verbal fluency measures in research on L1 attrition with long-term immigrants (Schmid and Jarvis 2014; Waas 1996; Yagmur 1997). These studies found that L1 fluency scores of immigrants in the new (L2-dominant) environment were significantly lower than fluency scores of L1 speakers in the home country. Linck et al. (2009) also found effects of relatively short-term residence abroad on L1 fluency. They reported that L1 fluency was lower and L2 fluency was higher in students of Spanish who had spent three months abroad compared to study-at-home students. While differences in fluency between monolinguals and bilinguals and between immigrants and home country residents are well-documented, more studies are needed about differences between groups of bilinguals who may maintain their L1 to different degrees over time (Dewaele 2004).

1 Note that there are intra and extralinguistic approaches to the definition and/or conceptualization of language dominance. See Liceras et al. 2016. 
Another task used to assess bilinguals' fluency, particularly with respect to their ability to control interference in lexical production, is the bilingual Stroop test. It is based on the original test developed by Stroop (1935) to investigate the effect of conflict and interference on naming responses. In one version of the test, participants have to name a color (e.g., $\bullet$ ) while controlling either a congruent additional stimulus (the printed word red in which color and word coincide) or an incongruent additional stimulus (the printed word blue in which print color and word conflict). Incongruent tasks take longer to complete than congruent ones because incongruent words interfere with color naming responses. The Stroop or interference effect is the difference between a neutral (baseline) response time (e.g., naming colors without any interfering words) and the naming time in the incongruent condition (e.g., naming colors while controlling interfering word meanings).

In the bilingual version of the Stroop test, color words are presented in both the bilingual's languages. In a within-language (intralingual) condition, the participants may have to name in English the print color of the words red (congruent color and word stimuli) and green (incongruent stimuli) (correct answer is red). In a between-language (interlingual) condition, they may have to name in English the print color of the Russian words зеленый 'green' (congruent stimuli) and красный 'red' (incongruent stimuli) (correct answer is green). Previous studies have found both intralingual and interlingual interference effects (Altarriba and Mathis 1997; Rosselli et al. 2000) although within-language effects were often larger than between-language effects (Chen and Ho 1986; Mägiste 1984). The ability to suppress incongruent stimuli was suggested to depend on the bilinguals' proficiency in the interfering language and in the response language as well as on the degree of similarity between the two involved languages. The higher the proficiency level (Mägiste 1984; Okuniewska 2007; Rosselli et al. 2000) and the larger the typological difference (Brauer 1998; Chen and Ho 1986) of the interfering language from the target language, the larger will be the interference effect. There is some evidence that highly proficient balanced bilinguals may be superior in controlling incongruent stimuli because they are assumed to display enhanced inhibitory control abilities compared to less proficient unbalanced bilinguals (Suarez et al. 2014; Zied et al. 2004). Other findings suggest that nonverbal intelligence is a better predictor of language control than proficiency and balance in bilinguals (Rosselli et al. 2016). Aging was reported to be detrimental to performance in bilingual Stroop tasks (Zied et al. 2004).

\subsection{The Present Study}

In this study, we explored the following questions: Do current language dominance patterns differ in two groups of younger and older Russian-English bilinguals who have spent similar amounts of time as immigrants in the U.S.? To what extent do lexical retrieval and language control skills in the L1 and the L2 differ in the two groups? Do the participants of the two groups experience different progress in L2 development and L1 maintenance in the lexical domain after having lived for seven or more years in an environment dominated by L2 use? This study is different from most research into Russian-English bilinguals in that it focuses on lexical fluency/speed of access and language control/the limitation of interference. It applies verbal fluency and Stroop tasks and introduces a new method to elicit parallel letter-fluency data for Russian and English, which represents an important methodological contribution. It also proposes a new conception of language balance, not in terms of proficiency, but in terms of stability of language systems. Normally, a bilingual's language system is seen as balanced if $\mathrm{s} /$ he is equally proficient in the two languages (Myers-Scotton 2008). Here, however, we conceive a system as balanced if processing is stable (and relatively resistant to interference) due to sustained language usage in specified domains. For this kind of balance, equal proficiency in the two languages is not needed.

\section{Hypotheses}

We applied verbal fluency tasks with letter and semantic category cues as well as bilingual Stroop tasks to measure bilinguals' lexical fluency and degree of control of the two languages to determine 
current language dominance patterns and infer the extent of L2 acquisition and L1 maintenance in younger and older Russian-English bilinguals. We expected the younger group to be overall more successful in L2 English acquisition and less successful in L1 Russian maintenance than the older group. Accordingly, we formulated the following hypotheses (H) 1-3 for between-group comparisons of letter fluency, category fluency, and color naming tasks and H 4-6 for within-group comparisons:

- H1: The younger group will be more fluent in the L2 (producing more words in the fluency tasks) than the older group.

- H2: The younger group will be less fluent in the L1 (producing fewer words in the fluency tasks) than the older group.

- H3: The younger more balanced bilingual group (with respect to proficiency) will show better control abilities (resulting in weaker interference effects in the Stroop tasks) than the older group.

- H4: The younger group will be more fluent in the L2 (producing more words in the fluency tasks) than the L1.

- H5: The older group will be more fluent in the L1 (producing more words in the fluency tasks) than the L2.

- H6a: Interference in the bilingual Stroop task will be stronger when caused by within-language conflict than between-language conflict (resulting in higher interference effect scores).

- H6b: Interference will be stronger when caused by conflicting words from the more dominant language than by words from the less dominant language (resulting in higher interference effect scores).

\section{Methods}

\subsection{Participants}

Participants were 43 Russian immigrants who came to two metropolitan areas in the southwestern U.S. between 1989 and 2003. They were divided into two groups based on age of arrival and years of formal education in the U.S. The younger group of participants $(n=22)$ had a mean $(M)$ age of 27.5 years at the time of study. They arrived in the U.S. as children or adolescents at the age of 20 or younger $(M$ age at arrival $=11.6$ years, range: $1-20)$ and had at least five years of formal education in the U.S. (M number of years of education in U.S. $=10.7)$. The older group of participants $(n=21)$ had a $M$ age of 58 years at the time of study ${ }^{2}$. They arrived in the U.S. as adults at the age of 23 or older ( $M$ age at arrival $=43$ years, range: $23-72$ ) and had no more than five years of formal education in the U.S. ( $M=2.2$ years). The younger group reported using English in more domains than Russian at the time of the study whereas the older group reported using Russian in more domains than English. Participants of both groups had lived a minimum of seven years in the U.S. The M length of U.S. residence at the time of the study was 14.1 years for the older group and 14.9 years for the younger group. Fifteen participants in the older group and 14 participants in the younger group were female. Seven participants in each group were male. Table 1 summarizes the main characteristics of the two participant groups.

2 Note that the $M$ age of the older bilinguals in this study (58) is somewhat lower and the range is wider compared to the "older bilinguals" investigated in other studies, e.g., Rosselli et al. 2000 (61) or Ivanova et al. 2016 (77). Most of the older-group participants in the present study might better be characterized as mid-age. 
Table 1. Participant characteristics of the two age-groups of Russian-English bilinguals.

\begin{tabular}{ccccc}
\hline \multirow{2}{*}{ Characteristics } & \multicolumn{2}{c}{ Older Group } & \multicolumn{2}{c}{ Younger Group } \\
\cline { 2 - 5 } & \multicolumn{2}{c}{$(\boldsymbol{n = 2 1 )}$} & \multicolumn{2}{c}{$(\boldsymbol{n = 2 2 )}$} \\
\hline Age at time of study & $\boldsymbol{M}$ & SD & $\boldsymbol{M}$ & SD \\
\hline Age at arrival in U.S. & 58 & 17.35 & 27.5 & 6.87 \\
Years of formal education in U.S. & 42.95 & 13.92 & 11.57 & 5.71 \\
Length of residence in U.S. & 2.18 & 1.65 & 10.71 & 3.78 \\
Proficiency in Russian, time of arrival & 14.09 & 4.01 & 14.95 & 5.42 \\
Proficiency in English, time of arrival & 6.87 & 0.48 & 5.57 & 1.98 \\
Proficiency in Russian, time of study & 1.93 & 1.16 & 2.01 & 1.68 \\
Proficiency in English, time of study & 6.85 & 0.44 & 5.73 & 1.36 \\
Russian usage domains, time of study & 4.4 & 1.29 & 6.64 & 0.61 \\
English usage domains, time of study & 5.59 & 1.44 & 6.9 & 3.59 \\
\hline
\end{tabular}

Proficiency was self-rated on a 7-point Likert scale from 1 (none) to 7 (native-like). Mean number of language usage domains for each language was out of 14 domains. M: mean; SD: standard deviation.

\subsection{Materials and Procedures}

Participants were asked to fill out a bilingual language background questionnaire. All questions were provided in both Russian and English to ensure that participants understood the questions regardless of their proficiency in either language. In the questionnaire, participants provided self-estimates of their language proficiencies in Russian and English at the time of study and in retrospect at the time of arrival in the U.S. (Table 1). The proficiency ratings for the time of arrival provided some general baseline data that would allow for inferences about participants' L2 acquisition as well as L1 maintenance.

Participants also provided information on language usage domains at the time of study. They had four possible responses to choose from for each of the language domains: Russian, English, both, or other. For example, if someone had marked three domains as "Russian", five as "English" and six as "Both", s/he would have obtained nine domain scores for Russian and 11 for English. The language usage domains included overall language use, communication at home, work, school, with spouse/partner, children, best friends, friends/acquaintances, language used for thinking, for entertainment, to express emotions, to swear in, to dream in, and for arithmetic mental computations. The $M$ numbers of domains in which the two languages were used by participants of both groups are displayed in Table 1. They should indicate overall language usage frequencies for Russian and English.

The overall structure of the experiment was as follows: verbal fluency tasks and Stroop tasks were given in one block in Russian as response language and in one block in English as response language. Each block consisted of eight tasks: three letter fluency tasks, two category fluency tasks, and three color-naming (Stroop) tasks. The language of instruction corresponded to the language of the testing session. The testing was voice-recorded. The order of the testing blocks in Russian and English was counterbalanced across participants. Between the testing blocks, participants were engaged in an informal bilingual interview with one of the researchers that lasted about $20 \mathrm{~min}$. The interview session was conducted to gather additional data and to reduce scaffolding and cross-language effects between blocks of fluency tasks. Before the start of the second block of the combined fluency and Stroop tasks, the researcher (who is fluent in both languages) increased the use of the response language of the following testing block and presented task instructions in that language. Reaction times were measured using a digital stop watch. Mean scores from the eight tasks in Russian and English were compared between groups (using Analysis of Variance (ANOVAs) tests) and within groups (using paired $t$-tests).

Letter fluency tasks. In the letter-fluency tasks, participants received a letter cue and had to produce as many words as possible that start with that letter. For the English task, letters $F, A$, and $S$ 
were used, which were shown to be adequate stimuli in terms of potential category size (how many possible words can be named) and frequency (how many frequently used words start with these letters) (Gollan et al. 2002; Rosselli et al. 2002). Participants had one minute to complete each sub-task.

A challenge of the letter-fluency tasks was that we needed to select letters from the Russian alphabet that would allow participants to generate similar amounts of words as in the task with the English letter cues $F, A$, and $S$. Previous research used the same initial letters as cues for word production although the frequencies of words starting with these letters differ considerably (Snodgrass and Tsivkin 1995). To select optimal cues, we compared the list of the 6318 most frequent English words from the British National Corpus (2017) and the list of the 5000 most frequent Russian words from Sharoff (2001). For each letter of the alphabets, we calculated the percentage of words starting with a particular letter that were part of the most frequently occurring words. In the end, we selected the Russian letters ДОС (DOS). They were the best match for English words with the initial letters FAS in their usage frequencies: words starting with ДОС represent $4.46 \%, 7.20 \%$, and $11.48 \%$, respectively, of the most frequent Russian words, and words starting in $F A S$ represent $4.83 \%, 6.77 \%$, and $11.48 \%$, respectively, of the most frequent English words in the frequency lists mentioned above. In both letter and category fluency tasks, participants were asked to avoid producing proper names and repetitions, as well as words in their various forms. It was emphasized that producing the same word with different endings within the same paradigm (e.g., noun declension) would be counted as only one entry. Only named words that started with the correct letter were counted as correct.

Category fluency tasks. In these tasks, participants were asked to name as many words as they could for the semantic categories of "animals" and "items of clothing". The time limit was again one minute for each sub-task. The same categories were used for L1 and L2 retrieval tasks because their size and frequency can be assumed to be similar (Snodgrass and Tsivkin 1995). Incorrect words, repetitions, cross-language intrusions, and words belonging to another category were not counted. A superordinate (e.g., bird) of a subcategory was only counted as correct when no subordinate member (e.g., sparrow) was named.

Stroop color-naming tasks. Following the category fluency tasks in a certain language block, three color-naming tasks were administered in the same response language to measure the bilinguals' fluency and ability to control interference while naming words. The Stroop tasks used in this study consisted of three conditions presented in a fixed order: color naming, within language (intralingual) incongruent color naming of color words, and between language (interlingual) incongruent color naming of color words. In each condition, participants were presented with a $9 \times 28 \mathrm{~cm}$ sheet of paper with eight horizontally arranged colored circles for color-naming. They were then shown an $11 \times 9 \mathrm{~cm}$ sheet of paper with eight vertically listed Russian color words in Times New Roman, font size 20, and an $11 \times 9 \mathrm{~cm}$ sheet of paper with eight vertically arranged English color words in Times New Roman, font size 20, or vice versa depending on the required response language. If Russian was the response language, the Russian color words were presented first and the English color words last. If English was the response language, then English color words were presented first and Russian words last. For each condition, the participants were instructed to name the colors as quickly and accurately as possible, without skipping any. The responses in the color-naming tasks were audio recorded. The times in seconds from onset of naming to completion of all eight stimuli were measured with a digital stop watch and used as scores.

The first color naming task was given as a baseline task. Participants had to name the color of eight circles to ensure that they knew the color names and to obtain baseline scores for color naming fluency. A shorter naming time in one of the languages was assumed to reflect a higher fluency in that language compared to the other less dominant language. Participants were presented with circles of colors in the following order and had to name them as quickly and accurately as possible. The names of colors below the circles are given here only for illustration purposes (Figure 1). 

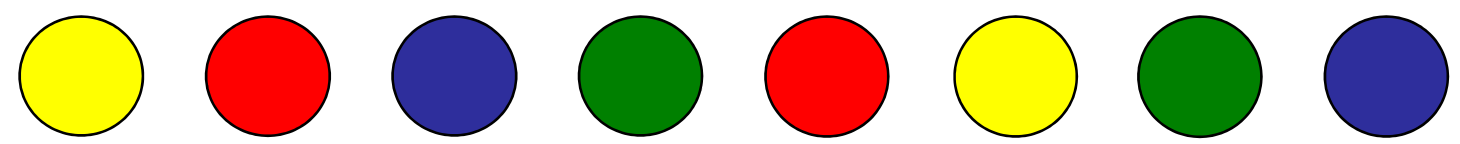

yellow red

blue

green

red

yellow

green

blue

Figure 1. Circles of colors presented as baseline task for Stroop tasks.

Next participants received a list of color words printed in different ink colors. They were asked to name the ink color of the words as quickly and accurately as possible. For example, the word blue printed in green needed to be named green. The incongruence between color word meaning and ink color was expected to cause a delay in the production of green because automatic reading would involve the activation of a semantically similar item (blue) that would interfere with the naming of the ink color. We assumed that the stronger the language of the printed word was, the stronger would be the interference with ink color naming and the longer would be the naming time difference compared to the baseline condition (the interference effect). There was an intralingual interference task and an interlingual task for the Russian color word naming task and for the English task. In both the Russian and the English sessions, the participants received the following two sets of stimuli (Tables 2 and 3):

Table 2. Stimuli 1 in Russian.

\begin{tabular}{cccccccc}
\hline Синий & Желтый & Красный & Зеленый & Желтый & Синий & Зеленый & Красный \\
\hline in green & in red & in blue & in yellow & in red & in green & in yellow & in blue \\
\hline
\end{tabular}

Table 3. Stimuli 2 in English.

\begin{tabular}{cccccccc}
\hline Blue & Yellow & Red & Green & Yellow & Blue & Green & Red \\
\hline in green & in red & in blue & in yellow & in red & in green & in yellow & in blue \\
\hline
\end{tabular}

During the Russian session, participants were asked first to name in Russian the ink color of the words written in Russian (stimuli 1 above generating intralingual interference). They then had to name in Russian the ink color of the words written in English (stimuli 2 above producing interlingual interference). In the English session analogously, participants had to name in English the colors of the English words in one sub-task and the colors of the Russian words in another task. The interference effects were calculated for each participant and each language by subtracting the baseline score of the circle color-naming task (without interfering stimuli) from the scores for naming the ink color of interfering words presented in each of the two languages.

The self-assessments, verbal fluency measures, and Stroop interference tasks taken together were assumed to provide a good overall picture of participant groups' current lexical fluency and their language dominance patterns. While these tasks did not enable us to objectively measure changes in participants' language fluency since immigration, they may allow us to infer the general trajectories of language development in the younger and older immigrants.

\section{Results}

\subsection{Verbal Fluency}

\subsubsection{Letter Fluency}

Table 4 presents the $M$ number of Russian and English words produced by participants of the older group and the younger group for each of the three letter fluency tasks and across the three 
sub-tasks. A two-factor ANOVA with independent variables of letter (three levels-one for each letter) and language (two levels: Russian and English) and the dependent variable of group revealed a significant interaction of language by group $(\mathrm{F}(1,41)=21.619, p<0.001)$ which suggests that the performances of the two groups differed.

Table 4. Mean number of Russian and English words produced by participants of the older group and the younger group for each of the three letter fluency tasks.

\begin{tabular}{|c|c|c|c|c|c|c|}
\hline \multirow[b]{2}{*}{ First Letter Cue } & \multicolumn{2}{|c|}{$\begin{array}{l}\text { Older Group } \\
\quad(n=21)\end{array}$} & \multicolumn{2}{|c|}{$\begin{array}{l}\text { Younger Group } \\
\qquad(n=22)\end{array}$} & \multirow[b]{2}{*}{$\mathbf{F}$} & \multirow[b]{2}{*}{$p$} \\
\hline & $M$ & SD & $M$ & SD & & \\
\hline Russian Д & 11.41 & 3.67 & 10.57 & 5.16 & 0.38 & 0.54 \\
\hline Russian $O$ & 9.5 & 4.29 & 8.71 & 4.27 & 0.36 & 0.55 \\
\hline Russian $C$ & 13.77 & 4.02 & 11.86 & 5.69 & 1.64 & 0.21 \\
\hline All Russian letter cues ДОС & 11.56 & 3.62 & 10.38 & 4.41 & 0.92 & 0.34 \\
\hline English $F$ & 8.5 & 4.04 & 10.48 & 2.98 & 3.3 & 0.08 \\
\hline English $A$ & 7.14 & 3.52 & 9.52 & 4.39 & 3.89 & 0.06 \\
\hline English $S$ & 10 & 4.6 & 13.9 & 4.07 & 8.64 & $0.01 * *$ \\
\hline All English letter cues FAS & 8.55 & 3.29 & 11.3 & 3.3 & 7.51 & $0.01 * *$ \\
\hline
\end{tabular}

Between-group analyses. F and $p$ values in Table 4 illustrate that the differences in $M$ scores of Russian word production for each of the letter cued-tasks and across the three tasks did not reach significance between the two groups $(p>0.05)$. The $M$ scores in English, on the other hand, were either significantly different between the groups (letter $S$ and the $M$ score across the three tasks, both $p<0.01$ ) or approached significant difference (letter $A, p<0.06$ and letter $F, p<0.08$ ). The younger group consistently scored higher in the English production tasks than the older group whereas both groups performed similarly well in the Russian tasks.

Within-group analyses. The older group's $M$ score across the three letter-cued subtasks was significantly higher in Russian than in the corresponding English tasks $(\mathrm{t}(21)=6.16, p<0.001)$. Paired $t$-tests used to compare the $M$ scores of words produced by the older group in the specific equivalent letter-cued tasks also yielded significant differences: Russian Д and English $F(\mathrm{t}(21)=3.56, p<0.002)$, Russian $O$ and English $A(\mathrm{t}(21)=3.16, p<0.005)$, and Russian $C$ and English $S(\mathrm{t}(21)=4.7, p<0.000)$. The older group consistently produced more words in the Russian letter-cued tasks than in the corresponding English tasks. The younger group's word production scores, on the other hand, did not differ significantly between English and Russian across the three letter-cued subtasks $(\mathrm{t}(20)=-1.32$, $p=0.2$ ) and none of the specific pairwise comparisons yielded significant differences (Russian $Д$ and English $F(\mathrm{t}(20)=0.09, p=0.93)$, Russian $O$ and English $A(\mathrm{t}(20)=-0.93, p=0.37)$, and Russian $C$ and English $S(\mathrm{t}(20)=-2.02, p=0.06)$.

\subsubsection{Category Fluency}

Table 5 provides the $M$ numbers of words produced in each specific category and across the two categories.

Between-group analyses. The language by group interaction in the two-factor ANOVA with independent variables of category (two levels: animals and clothing) and language (two levels: Russian and English) and the dependent variable of group was found significant $(\mathrm{F}(1,41)=21.37, p<0.001)$. Subsequent one-way ANOVAs revealed significant differences between the younger and the older groups in their performance in the English category fluency task $(p<0.001$ for each category and for the $M$ score across the two categories). None of the Russian category fluency scores showed significant differences between the younger and the older groups (all $p>0.05$ ). 
Table 5. Mean number of Russian and English words produced by participants of the older group and the younger group for each of the category fluency tasks.

\begin{tabular}{ccccccc}
\hline & \multicolumn{2}{c}{$\begin{array}{c}\text { Older Group } \\
(\boldsymbol{n}=\mathbf{2 1})\end{array}$} & $\begin{array}{c}\text { Younger Group } \\
(\boldsymbol{n}=\mathbf{2 2})\end{array}$ & & & \\
\hline Category cue & $\boldsymbol{M}$ & SD & $\boldsymbol{M}$ & SD & F & $\boldsymbol{p}$ \\
\hline Animals in Russian & 18.41 & 6.49 & 15.62 & 7.68 & 1.66 & 0.20 \\
Clothing in Russian & 18.55 & 5.98 & 17.81 & 6.55 & 0.15 & 0.70 \\
Both categories in Russian & 18.48 & 5.65 & 16.71 & 6.79 & 0.86 & 0.36 \\
Animals in English & 12.73 & 5.9 & 18.24 & 5.08 & 10.74 & $0.00^{* *}$ \\
Clothing in English & 13.14 & 4.22 & 19.43 & 4.57 & 22.03 & $0.00^{* *}$ \\
Both categories in English & 12.93 & 4.4 & 18.83 & 4.19 & 20.27 & $0.00^{* *}$ \\
\hline
\end{tabular}

Within-group analyses. The older group's $M$ score across the two category fluency tasks was significantly higher in Russian than in English $(\mathrm{t}(21)=7.04, p<0.000)$. The older group produced more words in the two Russian fluency tasks than in the corresponding English tasks: Russian animals and English animals $(\mathrm{t}(21)=5.52, p<0.000)$, and Russian clothing and English clothing $(\mathrm{t}(21)=5.95$, $p<0.000)$. The younger group's word production scores did not differ significantly between English and Russian across the two category fluency subtasks ( $\mathrm{t}(20)=-1.43, p=0.17)$, and none of the two pairwise comparisons yielded significant differences (Russian animals and English animals $(\mathrm{t}(20)=1.27, p=0.18)$, and Russian clothing and English clothing $(\mathrm{t}(20)=-1.43, p=0.22)$.

In sum and in line with participants' self-rated proficiencies, in both the letter and category fluency tasks, the younger group displayed a higher fluency in English L2 than the older group, whereas both groups maintained a similarly high fluency in Russian L1. The differences were more pronounced in the category fluency tasks than in the letter-fluency tasks.

\subsection{Stroop Color-Naming}

Participants completed three color-naming tasks in Russian: (1) naming the ink color of circles in Russian, (2) naming the color of words written in Russian, and (3) naming the color of words written in English. They also had to complete three color-naming tasks in English: (1) naming the ink color of circles in English, (2) naming the color of words written in English, and (3) naming the color of words written in Russian. Faster response times for color-naming in the baseline tasks were assumed to indicate a higher fluency in the given language. Response time differences in the incongruent tasks compared to the baseline tasks (the interference effects) were expected to reveal effects of language proficiency, superiority of within-language interference, and superiority of balanced bilingualism (in terms of proficiency). Table 6 displays the $M$ response times from participants of each group to complete the three sub-tasks and a $M$ response time score across all three tasks.

Table 6. Mean numbers of seconds needed to complete the color-naming tasks in Russian and English and interference effect scores by participants of the older group and the younger group.

\begin{tabular}{|c|c|c|c|c|c|c|}
\hline \multirow[b]{2}{*}{ Naming Task in Language (Cues) } & \multicolumn{2}{|c|}{$\begin{array}{l}\text { Older Group } \\
\quad(n=21)\end{array}$} & \multicolumn{2}{|c|}{$\begin{array}{l}\text { Younger Group } \\
\quad(n=22)\end{array}$} & \multirow[b]{2}{*}{$\mathbf{F}$} & \multirow[b]{2}{*}{$p$} \\
\hline & $M$ & SD & $M$ & SD & & \\
\hline Color in Russian (circles) & 6.05 & 1.99 & 4.86 & 1.62 & 5.33 & 0.03 * \\
\hline Color in Russian (English words) & 8.10 & 3.32 & 7.90 & 4.31 & 0.47 & 0.50 \\
\hline Color in Russian (Russian words) & 8.33 & 2.56 & 7.14 & 2.22 & 3.55 & 0.07 \\
\hline Color in Russian (Mean) & 7.49 & 2.32 & 6.63 & 2.36 & 2.35 & 0.13 \\
\hline Interference in Russian (English words) & 2.05 & 2.52 & 3.05 & 2.22 & 1.17 & 0.29 \\
\hline Interference in Russian (Russian words) & 2.29 & 2.08 & 2.29 & 2.35 & 0.00 & 1.00 \\
\hline
\end{tabular}


Table 6. Cont.

\begin{tabular}{|c|c|c|c|c|c|c|}
\hline \multirow[b]{2}{*}{ Naming Task in Language (Cues) } & \multicolumn{2}{|c|}{$\begin{array}{l}\text { Older Group } \\
\quad(n=21)\end{array}$} & \multicolumn{2}{|c|}{$\begin{array}{l}\text { Younger Group } \\
\quad(n=22)\end{array}$} & \multirow[b]{2}{*}{$\mathbf{F}$} & \multirow[b]{2}{*}{$p$} \\
\hline & $M$ & SD & $M$ & SD & & \\
\hline Color in English (circles) & 7.57 & 3.99 & 4.43 & 1.33 & 12.79 & $0.00 * *$ \\
\hline Color in English (English words) & 11.00 & 7.04 & 7.48 & 1.97 & 5.52 & $0.02 *$ \\
\hline Color in English (Russian words) & 9.62 & 4.22 & 6.52 & 2.18 & 8.59 & $0.01 * *$ \\
\hline Color in English (Mean) & 9.40 & 4.84 & 6.14 & 1.21 & 8.82 & $0.00 * *$ \\
\hline Interference in English (English words) & 3.43 & 3.83 & 3.05 & 2.01 & 0.16 & 0.69 \\
\hline Interference in English (Russian words) & 2.05 & 2.71 & 2.10 & 2.57 & 0.00 & 0.95 \\
\hline
\end{tabular}

Between-group analyses. A two-factor ANOVA with independent variables of interfering language (three levels: none, English and Russian) and response language (two levels: Russian and English) and the dependent variable of group revealed a significant language by group interaction $(\mathrm{F}(1,41)=7.46, p<0.01)$. Subsequent one-way ANOVAs, which compared the two groups' $M$ response times in the various Russian color-naming tasks, revealed a significant difference only for the baseline task of color-naming $(\mathrm{F}(1,42)=5.33, p<0.05)$. The younger group was faster than the older group in the baseline naming task in Russian which probably reflects a young-age advantage in general naming speed (Zied et al. 2004). However, when faced with conflicting word meanings from both Russian and English words, the younger group's advantage disappeared and performance was no different from the older group (all $p>0.05$ ).

All $M$ scores of color naming times in English differed significantly between the two groups (all $p<0.02$ ). The younger group consistently produced faster responses in English in all sub-tasks. None of the four one-way ANOVAs that compared interference effect scores between the groups revealed significant differences (all $p>0.05$ ) which suggests that overall both groups coped equally well with interference relative to their performance in the baseline task. This implies that we did not find an advantage of balanced bilinguals in terms of proficiency (the younger group) in their ability to control interference compared to less balanced bilinguals (the older group) as stated in hypothesis 3 , which needs to be rejected.

Within-group analyses. The older group's $M$ scores for naming times in Russian were consistently lower compared to English in all sub-tasks. Pairwise $t$-tests yielded the following differences: Naming the color of circles in Russian vs. naming the color of circles in English ( $t(21)=-2.75, p<0.01)$, naming in Russian the ink color of words written in English vs. naming in English the ink color of words written in English ( $t(21)=-2.82, p<0.01)$, and naming in Russian the ink color of words written in Russian vs. naming in English the ink color of words written in Russian $(t(21)=-2.64, p<0.06)$. The latter comparison only approached significance. On the other hand, none of the younger group's $M$ naming times in Russian were significantly different from the naming times in English $(p>0.05$ for all three tasks) which is consistent with the findings from the verbal fluency tasks and the assumption that the younger group's participants are relatively balanced bilinguals in terms of proficiency.

Various paired $t$-tests were used to compare the difference scores within each group to examine whether there is increased interference from the more dominant languages compared to the less-dominant languages. None of the comparisons showed significant differences (all $p>0.05$ ). Similarly, the comparison of within-language interference effects and between-language interference effects did not yield significant differences in any response language in both groups (all $p>0.05$ ). Due to the lack of significant differences in interference scores in both analyses, we needed to reject the assumptions of hypotheses $6 \mathrm{a}$ and $6 \mathrm{~b}$ that words from within the response language and words of more dominant languages generate larger interference effects. 


\section{Discussion}

In this study, we investigated language dominance, fluency and control patterns of two age groups of Russian-English bilinguals who immigrated to the U.S. and who had as groups spent similar amounts of time in this country. In addition to self-assessments of current L1 and L2 proficiencies and estimated respective proficiencies at the time of arrival in the U.S., we used three verbal fluency task types to measure the bilinguals' current lexical production skills: three letter fluency tasks, two semantic category fluency tasks, and a bilingual version of the Stroop test with three sub-tasks. The data, we hoped, would allow us to make informed inferences about the two group's overall success in L2 acquisition, L1 maintenance, and language control with a focus on the lexical domain. It also led us to rethink and redefine the concept of language balance in bilinguals.

\subsection{Language Dominance and Verbal Fluency}

Retrospective self-assessment scores suggested that both groups had about similar proficiency levels in Russian L1 and English L2 at the time of arrival. Based on previous research findings, we hypothesized that the younger group would be more successful in acquiring the L2 and less successful in maintaining the L1 than the older group. In other words, in a between-group comparison, we expected the younger group to be more fluent in the L2 and less fluent in the L1 than the older group. We also expected to find within-group differences: the younger group was expected to be more fluent in the L2 than the L1 (reflecting a change in language dominance), and the older group was expected to be more fluent in the L1 than the L2 (reflecting a continuing L1 dominance).

Between-group analyses showed that the younger group was more fluent in the L2 English (reflected in higher scores in the verbal fluency tasks, faster response times in the Stroop tasks, and higher self-assessment scores) than the older group. This confirmed hypothesis H1 and the assumption that younger learners are overall more successful in L2 attainment than older learners (Abrahamsson and Hyltenstam 2009; Flege 1999; Flege et al. 2006). The advantage of the younger L2 learners over the older ones could be attributed to either age of arrival or years of formal education in the U.S. More likely is that both factors had a combined impact on the rate and attainment of verbal fluency of the younger group. Compared to older immigrants, younger immigrants can be expected to receive more and qualitatively different L2 input through social networks and interaction in linguistically more diverse domains such as school, work, friends, and entertainment and use the L2 more variably, which results in a higher L2 proficiency. Participants' self-reports on language usage domains confirmed that the older group predominantly used Russian (in 12 domains on average) compared to English (in six domains) while the younger group used English in 11 domains and Russian in seven domains including at home and with friends. The domain of school and formal education in which L2 literacy and academic skills were developed in the younger participants must have constituted a major learning advantage over the older participants who had less formal education in the L2. The expectation expressed in $\mathrm{H} 2$ that the younger group would be less fluent in the L1 Russian than the older group was not confirmed by the data. While the older participants on average tended to be somewhat more fluent in Russian than the younger participants, none of the measures showed significant differences.

Findings from within-group analyses were in line with findings from between-group analyses. They confirmed our hypothesis H5: The older group was shown to be more fluent (producing more words and responding faster) in the L1 Russian than the L2 English, a finding that underscores the older participants' continuing dominance in Russian. The younger group participants, on the other hand, exceeded our expectations with respect to maintained fluency in the L1 so that we had to reject H4: Although the younger group appeared to be somewhat more fluent in the L2 than the L1, none of the differences in verbal fluency scores between the two languages reached significance. Note also that the younger group's $M$ score of self-reported L1 proficiency for time of study slightly exceeded the corresponding $M$ score for time of arrival. This suggests that the younger bilinguals did not 
only maintain their L1 skills in an English-dominant environment, they may even have developed them further.

The findings of this study are consistent with results reported on verbal fluency in Spanish-English bilinguals in the U.S. who acquired Spanish as an L1 and English as an L2 and who continued using both languages on a daily basis (Rosselli et al. 2000). These Spanish-English bilinguals reportedly did not experience L1 attrition. The lack of substantial attrition in L1 fluency, not only in the older, but also in the younger group of our study is probably partially due to the younger group's relatively high $M$ age of arrival in the U.S. Bilinguals' susceptibility to L1 attrition begins to decline at the end of the first decade of childhood (Köpke and Schmid 2004; Pallier 2007). The $M$ age of arrival of the younger participants in our study was 12 years. By the time of arrival, their L1 must have stabilized already, and as most of them came in intact families, they continued using the L1 at least in the family domain. Language practice at home has been shown to be a strong predictor for L1 maintenance (Kenji and d'Andrea 1992; Isurin and Ivanova-Sullivan 2008; Ritter 2014; Smyslova 2012). As such, language attitudes, language usage strategies and practices at home are crucial for the maintenance of L1 skills. Our finding about L1 maintenance is quite encouraging in that it demonstrates that children and adolescents of immigrant families can be very successful in maintaining and further developing their L1 while successfully acquiring an L2 providing that learner-internal and environmental factors are supportive (Jia and Aaronson 2003). Note, however, that the lack of apparent L1 attrition does not mean that the Russian/English bilinguals of this study are not any different from monolingual speakers of Russian. They will necessarily perform differently from monolinguals due to the different language usage patterns they display. One should not expect bilinguals to be two monolinguals in one person and apply monolingual standards or expectations with regard to proficiency (Grosjean and Li 2013). Adding a Russian-speaking monolingual group to the present study design would have allowed us to investigate these differences. Unfortunately, this was not possible.

\subsection{Language Control-The Suppression of Interference}

A hypothesis that could not be upheld was $\mathrm{H} 3$, the expectation that the younger, in terms of proficiency, more balanced bilingual group would show overall weaker interference effects and better control abilities (resulting in faster response times) in Stroop color-naming tasks than the older group. Although the younger bilinguals in our study were generally faster in verbal fluency and color-naming tasks reflecting a younger-age advantage in word retrieval speed (Zied et al. 2004), they did not demonstrate any advantages in coping with interference according to the Stroop (interference effect) scores. Thus, our findings do not confirm results from previous studies, which suggest that highly proficient balanced bilinguals are superior in controlling interference because of enhanced inhibitory control abilities compared to less proficient unbalanced bilinguals (Suarez et al. 2014; Zied et al. 2004). Balanced bilingualism is usually understood as a kind of bilingualism with similar proficiency levels in the two languages and is established through language proficiency testing (Rosselli et al. 2016). We are proposing here that it is not balance in bilingual proficiency that positively affects language control abilities, but balance as stability of language systems. Stability of language systems can be achieved if bilingual usage patterns remain relatively constant over several years and if no radical changes in language learning and maintenance efforts are required.

Research on dynamic aspects of individual bilingualism suggests that bilinguals go through periods of instability and language system restructuring, on the one hand, and periods of relative stability, on the other hand (Herdina and Jessner 2002; Schmid et al. 2013). Cross-language influence and lack of language control is more likely to occur in periods of instability compared to periods of balance (Ecke and Hall 2013; Opitz 2013). Both groups of bilinguals in the present study appear to have reached a period of stability in their language system and usage patterns which enables them to exercise sufficient control over their languages in the domains that they are using them. While this research points to dynamic changes in bilinguals' language usage and proficiency patterns, more fine-grained studies are needed to ascertain the kind of input, time, and usage that will lead to stable 
or instable language systems and control abilities. They will also have to control for other potential factors, such as nonverbal intelligence (Rosselli et al. 2016) and age (Ivanova et al. 2016) which may affect executive functioning including language control.

Whereas our verbal fluency data show some reduction in bilinguals' speed of lexical retrieval with increasing age, the data from Stroop tasks do not point to a decline in language control in older adults. However, these aging-related findings need to be interpreted with caution because our older group was relatively young ( $M=59$ years) and heterogeneous compared to populations that are normally studied with respect to the effects of older age on language and cognitive control ( $M=77$ years, for example, in Ivanova et al. 2016).

A related within-group analysis concerned the relative strength of interference effects based on two possible factors. In H6a, we predicted that interference would be stronger when caused by within-language (intralingual) conflict than by between-language (interlingual) conflict (Chen and Ho 1986; Mägiste 1984); and in H6b we expected interference to be stronger when caused by conflicting words from the more dominant language than by words from the less dominant language (Mägiste 1984; Rosselli et al. 2000). None of the predictions, however, were confirmed by the data. Words from English and Russian and from within and across languages produced a retrieval slowdown in the two bilingual groups. This is consistent with Altarriba and Mathis (1997) and Okuniewska (2007) who did not find within-language superiority effects. The finding that even the non-dominant L2 generated interference in the older group supports Pavlenko and Malt (2011) claim that (modest) L2 influence on L1 production may occur in any bilingual group of speakers if there is moderate exposure to the L2.

In this study, we used letter and category fluency tasks exclusively as measures of lexical retrieval skills, and Stroop tasks as measures of language control and the suppression of interference. We need to acknowledge though that researchers have also considered letter and category fluency tasks as tools that may tap into aspects of inhibitory control, i.e., the ability to inhibit responses to irrelevant information in cognitive or language-related tasks (e.g., Bialystok et al. 2008; Escobar et al. 2018; Friesen et al. 2015). Category fluency tasks, which resemble every-day tasks, like generating a shopping list, require response inhibition: Participants have to inhibit the retrieval of semantically related items that are not part of the required category. Letter fluency tasks, on the other hand, are rare in real-life speech production. They require interference suppression: here, participants have to actively inhibit semantically and formally related words and resort to unusual retrieval strategies. Some researchers caution that the hybrid nature of the verbal fluency tasks may limit their applicability to the study of executive control (Shao et al. 2014). More research is needed to ascertain the different inhibitory control processes in younger, older, balanced, and unbalanced bilinguals, and how they relate to verbal ability, including vocabulary size and lexical fluency.

\subsection{Methodological Contributions and Limitations}

One contribution of this study to research methodology was the identification of Russian letters ДОС (DOS) as best matches for the frequently used English letter stimuli FAS based on an analysis of usage frequencies of words starting with these and other letters. Future studies that intend to apply letter fluency tasks could use the identified letter cue equivalents in cross-language analyses or in studies with English-Russian bilinguals.

The reported study, without doubt, has its limitations. A first limitation relates to the sample of Russian-English bilinguals that we were able to recruit. Dividing the participants into two groups based on age of arrival and years of education in the U.S. did not surmount a certain degree of heterogeneity within the groups. Apart from age of arrival, within-group variation may also concern language usage (see Ritter 2014, on variability in L1 usage and maintenance in Russian immigrant families in Germany). Secondly, the use of participant's self-assessment of L1 and L2 proficiencies at time of arrival is only a rough estimate of language dominance and proficiency. More objective pre- and posttests of language dominance in a longitudinal study should be preferred if they are 
possible in future studies. Thirdly, although we tried to reduce scaffolding and cross-language effects by adding an interview session between language blocks of fluency and Stroop tasks, we cannot rule out order effects completely. As one reviewer suggested, it would be recommendable to conduct analyses examining order effects, as well as analyses examining repetition of exemplars across the two languages in future studies.

Finally, it needs to be stressed that this study focused on language dominance based on spoken lexical fluency leaving aside grammatical knowledge and literacy skills in the bilinguals' two languages. It may well be that the participants display different dominance and proficiency patterns in reading and writing skills which are likely to be less developed than speaking skills in heritage speakers (e.g., Kagan 2005; Smyslova 2012).

\section{Conclusions}

We investigated language fluency and dominance patterns of two age groups of Russian-English bilinguals who immigrated to the U.S. and who, as groups, had spent similar amounts of time in this country. In addition to self-assessments of language proficiencies at time of study and time of arrival, we used letter fluency, semantic category fluency, and bilingual Stroop tasks to measure the bilinguals' current lexical fluency and their ability to cope with within- and between-language interference.

This study's findings are good news in two respects: first, we found that the young Russian immigrants were very successful in both maintaining their L1 fluency and developing English L2 fluency. They managed to become relatively balanced bilinguals in terms of proficiency, highly proficient in both spoken languages. While an increasingly dominant L2 will often have a noticeable impact on L1 skills in the dynamic unfolding of bilingual proficiency patterns, our study demonstrated that it does not have to lead to a decline of verbal fluency and to attrition in the L1. Children and adolescents who immigrate after the first decade in life and who continue using the L1 consistently in some domains have a very good chance of developing additive bilingualism, successfully building L2 fluency while maintaining fluency in the L1.

Secondly, the older immigrants, unbalanced bilinguals in terms of proficiency, who remained dominant in their L1 and who did not become as fluent in the L2 as the young immigrants, displayed comparable abilities in language control and the suppression of interference. Language control abilities do not have to be dependent on language balance in terms of proficiency. Instead, we suggest that they depend on balance as stability in language systems and language usage. The older immigrants, like most of the world's bilinguals, are not equally proficient in their two languages, but they use them consistently and continuously in certain domains and are able to control them sufficiently well in every-day life.

Author Contributions: P.E. and E.S. conceived and designed the experiments; E.S. performed the experiments; E.S. analyzed the data; P.E. wrote the paper.

Funding: This research received no external funding.

Acknowledgments: We would like to thank the anonymous reviewers and the Editors for their helpful comments and suggestions.

Conflicts of Interest: The authors declare no conflict of interest.

\section{References}

Abrahamsson, Niclas, and Kenneth Hyltenstam. 2009. Age of Onset and Nativelikeness in a Second Language: Listener Perception Versus Linguistic Scrutiny. Language Learning 59: 249-306. [CrossRef]

Altarriba, Jeanette, and Katherine M. Mathis. 1997. Conceptual and Lexical Development in Second Language Acquisition. Journal of Memory and Language 36: 550-68. [CrossRef]

Andrews, David R. 2000. Heritage Learners in the Russian Classroom: Where Linguistics Can Help. ADFL Bulletin 31: 39-44. [CrossRef] 
Benmamoun, Elabbas, Silvina Montrul, and Maria Polinsky. 2010. White Paper: Prolegomena to Heritage Linguistics. Harvard University, Cambridge, MA, USA. Available online: https:/ / scholar.harvard.edu/files / mpolinsky / files/hl_white_paper_june_12.pdf (accessed on 2 May 2018).

Bialystok, Ellen, Fergus IM Craik, and Gigi Luk. 2008. Lexical Access in Bilinguals: Effects of Vocabulary Size and Executive Control. Journal of Neurolinguistics 21: 522-38. [CrossRef]

Birdsong, David. 2014. Dominance and Age in Bilingualism. Applied Linguistics 35: 374-92. [CrossRef]

Brauer, Markus. 1998. Stroop Interference in Bilinguals: The Role of Similarity between the two Languages. In Foreign Language Learning. Edited by Alice F. Healy and Lyle E. Baurne Jr. Mahwah: Erlbaum, pp. 317-37.

British National Corpus. 2017. Available online: http:/ / www.natcorp.ox.ac.uk/ (accessed on 9 February 2017).

Bylund, Emanuel, Niclas Abrahamsson, and Kenneth Hyltenstam. 2012. Does First Language Maintenance Hamper Nativelikeness in a Second Language? Studies in Second Language Acquisition 34: 215-41. [CrossRef]

Chen, Hsuan-chih, and Connie Ho. 1986. Development of Stroop Interference in Chinese-English Bilinguals. Journal of Experimental Psychology: Learning, Memory, and Cognition 12: 397-401. [CrossRef]

De Bot, Kees, and Wander Lowie. 2010. On the Stability of Representation in the Multilingual Lexicon. In Cognitive Processing in Second Language Acquisition. Edited by Martin Pütz and Laura Sicola. Amsterdam: John Benjamins, pp. 117-34.

Dewaele, Jean-Marc. 2004. Perceived Language Dominance and Language Preference for Emotional Speech: The Implications for Attrition Research. In First Language Attrition: Interdisciplinary Perspectives on Methodological Issues. Edited by Monika Susanne Schmid, Barbara Köpke, Merel Keijzer and Lina Weilemar. Amsterdam: John Benjamins, pp. 81-105.

Dubinina, Irina, and Maria Polinsky. 2013. Russian in the USA. In Slavic Languages in Migration. Edited by Michael Moser and Maria Polinsky. Wien: University of Vienna, pp. 1-28.

Ecke, Peter, and Christopher J. Hall. 2013. Tracking Tip-of-the-Tongue States in a Multilingual Speaker: Evidence of Attrition or Instability in Lexical Systems? International Journal of Bilingualism 17: 734-51. [CrossRef]

Ecke, Peter. 2004. Language Attrition and Theories of Forgetting: A Cross-Disciplinary Review. International Journal of Bilingualism 8: 321-54. [CrossRef]

Escobar, Gloria Pino, Marina Kalashnikova, and Paola Escudero. 2018. Vocabulary Matters! The Relationship between Verbal Fluency and Measures of Inhibitory Control in Monolingual and Bilingual Children. Journal of Experimental Child Psychology 170: 177-89. [CrossRef] [PubMed]

Flege, James E. 1999. Age of Learning and Second-Language Speech. In Second Language Acquisition and the Critical Period Hypothesis. Edited by David Birdsong. Hillsdale: Lawrence Erlbaum, pp. 101-32.

Flege, James Emil, David Birdsong, Ellen Bialystok, Molly Mack, Hyekyung Sung, and Kimiko Tsukada. 2006. Degree of Foreign Accent in English Sentences Produced by Korean Children and Adults. Journal of Phonetics 34: 153-75. [CrossRef]

Friesen, Deanna C., Lin Luo, Gigi Luk, and Ellen Bialystok. 2015. Proficiency and Control in Verbal Fluency Performance across the Lifespan for Monolinguals and Bilinguals. Language, Cognition and Neuroscience 30: 238-50. [CrossRef] [PubMed]

Gollan, Tamar H., Rosa I. Montoya, and Grace A. Werner. 2002. Semantic and Letter Fluency in Spanish-English Bilinguals. Neuropsychology 16: 562-76. [CrossRef] [PubMed]

Grosjean, François, and Ping Li. 2013. The Psycholinguistics of Bilingualism. Malden: Wiley-Blackwell.

Herdina, Philip, and Ulrike Jessner. 2002. A Dynamic Model of Multilingualism: Perspectives of Change in Psycholinguistics. Clevedon: Multilingual Matters.

Isurin, Ludmila, and Tanya Ivanova-Sullivan. 2008. Lost in Between: The Case of Russian Heritage Speakers. Heritage Language Journal 6: 72-104.

Isurin, Ludmila. 2000. Deserted Island or a Child's First Language Forgetting. Bilingualism: Language and Cognition 3: 151-66. [CrossRef]

Isurin, Ludmila. 2007. Teachers' Language: L1 Attrition in Russian-English Bilinguals. The Modern Language Journal 91: 357-71. [CrossRef]

Isurin, Ludmila. 2013. Memory and First Language Forgetting. In Memory, Language, and Bilingualism: Theoretical and Applied Approaches. Edited by Jeanette Altarriba and Ludmila Isurin. Cambridge: Cambridge University Press, pp. 319-48.

Ivanova, Iva, Mayra Murillo, Rosa I. Montoya, and Tamar H. Gollan. 2016. Does Bilingual Language Control Decline in Older Age? Linguistic Approaches of Bilingualism 6: 86-118. [CrossRef] [PubMed] 
Jia, Gisela, and Doris Aaronson. 2003. A Longitudinal Study of Chinese Children and Adolescents Learning English in the United States. Applied Psycholinguistics 24: 131-61. [CrossRef]

Kagan, Olga, and Kathleen Dillon. 2004. Heritage Speakers' Potential for High-Level Language Proficiency. In Advanced Foreign Language Learning: A Challenge to College Programs. Edited by Heidi Byrnes and Hiram H. Maxim. Boston: Heinle, pp. 99-112.

Kagan, Olga. 2005. In Support of Proficiency-Based Definition of Heritage Learners: The Case of Russian. International Journal of Bilingual Education and Bilingualism 8: 213-21. [CrossRef]

Kenji, Hakuta, and Daniel d'Andrea. 1992. Some Properties of Bilingual Maintenance and Loss in Mexican Background High-School Students. Applied Linguistics 13: 72-99. [CrossRef]

Köpke, Barbara, and Monika S. Schmid. 2004. Language Attrition: The Next Phase. In First Language Attrition: Interdisciplinary Perspectives on Methodological Issues. Edited by Monika S. Schmid, Barbara Köpke, Merel Keijzer and Lina Weilemar. Amsterdam: John Benjamins, pp. 1-43.

Laleko, Oksana. 2007. A Study of Language Attrition: American Russian in Minnesota. Texas Linguistic Forum 51: 103-12.

Liceras, Juana M., Raquel Fernández Fuertes, and Rachel Klassen. 2016. Language Dominance and Language Nativeness: The View from English-Spanish Code-switching. In Spanish-English Codeswitching in the Caribbean and the U.S. Edited by Rosa E. Guzzardo Tamargo, Catherine M. Mazak and M. Carmen Parafita Couto. Amsterdam: Benjamins, pp. 107-38.

Linck, J. A., J. F. Kroll, and G. Sunderman. 2009. Losing Access to the Native Language While Immersed in a Second Language: Evidence for the Role of Inhibition in Second Language Learning. Psychological Science 20: 1507-15. [CrossRef] [PubMed]

Mägiste, Edith. 1984. Stroop Tasks and Dichotic Translation: The Development of Interference Patterns in Bilinguals. Journal of Experimental Psychology: Learning, Memory, and Cognition 10: 304-15. [CrossRef]

Mikhaylova, Anna. 2006. Second Language Influence among Russian-English Late Bilinguals: Experimental Study. Inostrannye Jazyki v Vysshej Shkole 3: 110-19.

Montrul, Silvina. 2015. The Acquisition of Heritage Languages. Cambridge: Cambridge University Press.

Muñoz, Carmen, and David Singleton. 2011. A Critical Review of Age-Related Research on L2 Ultimate Attainment. Language Teaching 44: 1-35. [CrossRef]

Myers-Scotton, Carol. 2008. Multiple Voices: An Introduction to Bilingualism. Maiden: Blackwell.

Okuniewska, Hanna. 2007. Impact of Second Language Proficiency on the Bilingual Polish-English Stroop Task. Psychology of Language and Communication 11: 49-63.

Opitz, Conny. 2013. A Dynamic Perspective on Late Bilinguals' Linguistic Development in an L2 Environment. International Journal of Bilingualism 17: 701-15. [CrossRef]

Pallier, Christophe. 2007. Critical Periods in Language Acquisition and Language Attrition. In Language Attrition: Theoretical Perspectives. Edited by Barbara Köpke, Monika S. Schmid, Merel C.J. Keijzer and Susan Dostert. Amsterdam: John Benjamins, pp. 155-68.

Pavlenko, Aneta, and Barbara C. Malt. 2011. Kitchen Russian: Cross-linguistic Differences and First-Language Object Naming by Russian-English Bilinguals. Bilingualism: Language and Cognition 14: 19-45. [CrossRef]

Pavlenko, Aneta. 2003. 'I feel clumsy speaking Russian': L2 Influence on L1 in Narratives of Russian L2 Users of English. In Effects of the Second Language on the First. Edited by Vivian Cook. Clevedon: Multilingual Matters, pp. 32-61.

Polinsky, Maria. 2006. Incomplete Acquisition: American Russian. Journal of Slavic Linguistics 14: 191-262.

Portocarrero, José S., Richard G. Burright, and Peter J. Donovick. 2007. Vocabulary and Verbal Fluency of Bilingual and Monolingual College Students. Archives of Clinical Neuropsychology 22: 415-22. [CrossRef] [PubMed]

Ritter, A. 2014. Bilingual Speech in Russian-German Language Contact: Findings Based on an Analysis of Natural Conversations in Russian-Speaking Immigrant Families in Germany. In Language Contacts at the Crossroads of Disciplines. Edited by Heli Paulasto, Lea Meriläinen, Helka Riionheimo and Maria Kok. Newcastle upon Tyne: Cambridge Scholars Publishing, pp. 251-79.

Rosselli, Mónica, Alfredo Ardila, Katia Araujo, Viviana A. Weekes, Virginia Caracciolo, Mabel Padilla, and Feggy Ostrosky-Solí. 2000. Verbal Fluency and Repetition Skills in Healthy Older Spanish-English Bilinguals. Applied Neuropsychology 7: 17-24. [CrossRef] [PubMed] 
Rosselli, Mónica, Alfredo Ardila, Mirtha N. Santisi, María Del Rosario Arecco, Judy Salvatierra, Alejandra Conde, and Bonie Lenis. 2002. Stroop Effect in Spanish-English Bilinguals. Journal of the Neuropsychological Society 8: 819-27. [CrossRef]

Rosselli, Mónica, Alfredo Ardila, Laxmi N. Lalwani, and Idaly Vélez-Uribe. 2016. The Effect of Language Proficiency on Executive Functions in Balanced and Unbalanced Spanish-English Bilinguals. Bilingualism: Language and Cognition 19: 489-503. [CrossRef]

Schmid, Monika S. 2011. Language Attrition. Cambridge: Cambridge University Press.

Schmid, Monika S., and Scott Jarvis. 2014. Lexical Access and Lexical Diversity in First Language Attrition. Bilingualism: Language and Cognition 17: 729-48. [CrossRef]

Schmid, Monika S., Barbara Köpke, and Kees De Bot. 2013. Language Attrition as a Complex, Non-linear Development. International Journal of Bilingualism 17: 675-82. [CrossRef]

Shao, Zeshu, Esther Janse, Karina Visser, and Antje S. Meyer. 2014. What do Verbal Fluency Tasks Measure? Predictors of Verbal Fluency Performance in Older Adults. Frontiers in Psychology 5: Article 772: 1-10. [CrossRef] [PubMed]

Sharoff, Sergei. 2001. The Frequency Dictionary for Russian. Available online: http:/ /www.artint.ru/projects / frqlist/frqlist-en.asp (accessed on 12 December 2017).

Smyslova, Alla. 2012. Low-Proficiency Heritage Speakers of Russian: Their Interlanguage System as a Basis for Fast Language (Re)Building. In Russian Language Studies in North America: New Perspectives from Theoretical and Applied Linguistics. Edited by Veronika Makarova. London: Anthem Press, pp. 161-91.

Snodgrass, Joan Gay, and Susanna Tsivkin. 1995. Organization of the Bilingual Lexicon: Categorical versus Alphabetic Cuing in Russian-English Bilinguals. Journal of Psycholinguistic Research 24: 145-63. [CrossRef]

Stroop, J. Ridley. 1935. Studies of Interference in Serial Verbal Reactions. Journal of Experimental Psychology 18: 643-62. [CrossRef]

Suarez, Paola A., Tamar H. Gollan, Robert Heaton, Igor Grant, Mariana Cherner, and the HNRC Group. 2014. Second-Language Fluency Predicts Native Language Stroop Effects: Evidence from Spanish-English Bilinguals. Journal of the International Neuropsychological Society 20: 342-48. [CrossRef] [PubMed]

Waas, Margit. 1996. Language Attrition Downunder: German Speakers in Australia. Frankfurt am Main: Lang.

Yagmur, Kutlay. 1997. First Language Attrition among Turkish Speakers in Sydney. Tilburg: Tilburg University Press. Zied, Kefi Mohamed, Allain Phillipe, Pinon Karine, Havet-Thomassin Valerie, Aubin Ghislaine, Roy Arnaud, and Le Gall Didier. 2004. Bilingualism and Adult Differences in Inhibitory Mechanisms: Evidence from a Bilingual Stroop Task. Brain and Cognition 54: 254-56. [CrossRef] [PubMed] 